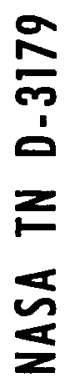

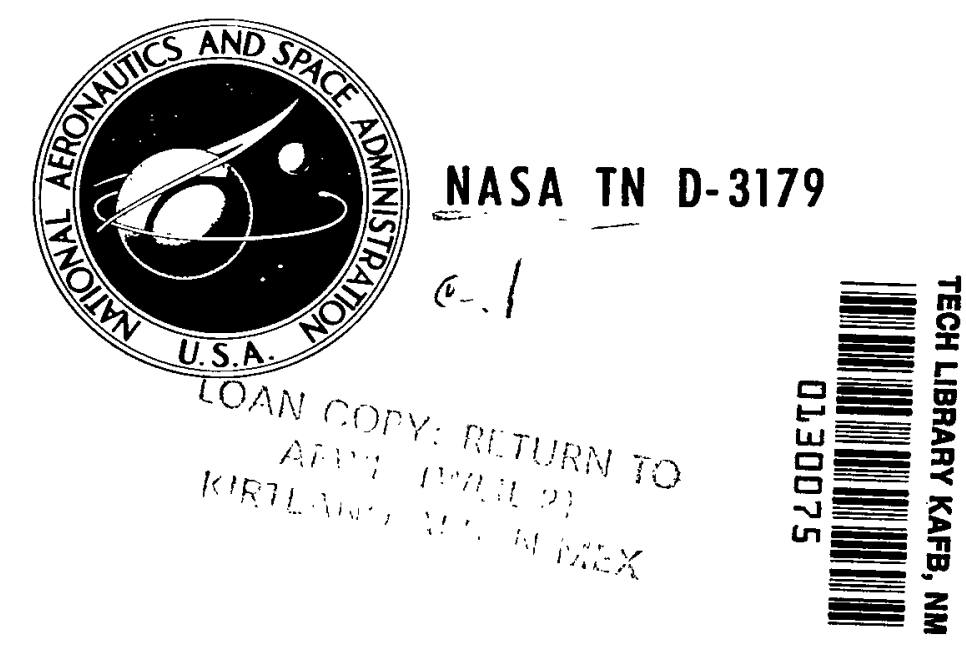

\title{
THERMOPOTENTIAL MEASUREMENTS OF ALKALI HALIDES
}

by Jacob Greenberg

Lewis Research Center

Cleveland, Obio

NATIONAL AERONAUTICS AND SPACE ADMINISTRATION - WASHINGTON, D. C. JangarY 1966 
NASA TN D-3179

THERMOPOTENTIAL MEASUREMENTS OF ALKALI HALIDES

By Jacob Greenberg

Lewis Research Center

Cleveland, Ohio

\section{NATIONAL AERONAUTICS AND SPACE ADMINISTRATION}

For sale by the Clearinghouse for Federal Scientific and Technical Information

Springfield, Virginia 22151 - Price $\$ 1.00$ 


\author{
THERMOPOTENTIAL MEASUREMENTS OF ALKALI HALIDES* \\ by Jacob Greenberg
}

Lewis Research Center

\title{
SUMMARY
}

It has been found that when sodium iodide, potassium iodide, cesium chloride, sodium chloride, and potassium chloride are subjected to thermal gradients, Seebeck coefficients are obtained that vary as a function of the salt and the average temperature. The Seebeck coefficients were found to increase, to reach a maximum of 2 to 3 millivolts per ${ }^{\circ} \mathrm{C}$, and then to decrease as the temperature was increased. This was usually found to occur within $100^{\circ} \mathrm{C}$ on either side of the melting point. It was possible to maintain a steady external flow of current of several milliamperes from the thermopotential developed in the cesium chloride cell.

At lower temperatures, it appears that cation migration is primarily responsible for the thermopotential, while at higher temperatures the thermopotential appears to be due to the anion migration.

\section{INIRODUCTION}

There are many reasons for interest in the electrical potentials developed when alkali halides are subjected to thermal gradients. First, the heating of these salts as they are used for metallurgical purposes, fuel-cell electrolytes, heat-transfer media, and thermal batteries is usually done in the presence of temperature gradients, and it is therefore important to know the effect of such temperature differences in establishing thermopotentials. These thermopotentials can influence the corrosion and reaction rate of the systems involved. Second, in order to evaluate alkali halides as possible thermoelectric materials, it is necessary to know the Seebeck coefficient $S=\Delta V / \Delta T$, where $V$ is voltage and $T$ is temperature. Third, a qualitative picture of the ionic processes involved in heating can be obtained. Traditionally, a molten salt thermocell consists of electrode materials which are reversible with respect to one of the ions of the salt. Such a cell would be silver-silver nitrate $\mathrm{Ag}\left|\mathrm{AgNO}_{3}\right| \mathrm{Ag}$ or chlorine-sodium chloride $\mathrm{Cl}_{2} \mid \mathrm{NaCl} / \mathrm{Cl}_{2}$ where the two temperatures are different. In these cases the thermopotential becomes a function not only of the potential developed in the salt as a result of the presence of a temperature gradient, but also of the potential developed by electron exchange at the electrodes, as well as the potential developed by the electrode materials themselves as a result of being at two different temperatures. However, if the

\section{5.}

\footnotetext{
*Presented at Electrochem. Soc. Meeting, San Francisco (Calif.), May 5-9,
} 


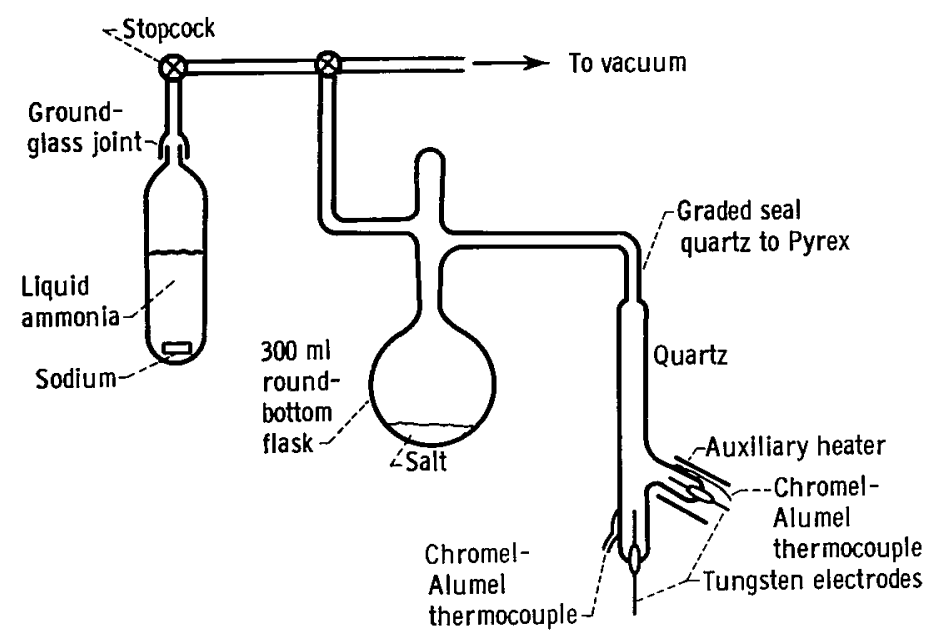

Flgure 1. - Diagram of apparatus used to purify salts and measure thermopotentials. thermopotentials of these salts can be measured with inert electrodes, then the electrical potential developed as a result of the temperature gradient is primarily a function of the ionic properties of the salt.

\section{EXPER IMEIVTAL PROCEDURE}

Anhydrous salts were prepared by washing with liquid ammonia. The more conventional methods of purifying metal halides involve heating the salt and treating the melt to remove hydrolysis products. The heating of the salts in the presence of water produces hy-

drolysis products, which are then responsible in part for the corrosive action of the melts. By treating the solid with liquid ammonia at low temperatures, the introduction of hydrolysis products is limited. The water present in the halides becomes associated with the ammonia and is carried out in the diffusion stream (ref. I).

The salts were purified in 300-milliliter round-bottom flasks. These halides were then transferred in the flasks to a quartz cell fitted with two tungsten electrodes. The tungsten electrodes were initially beaded with a grading glass of slightly lower melting point than quartz. This was done in such a manner that the tungsten surface in contact with the graded glass was free of oxides. The seal was formed essentially by the compression of the metal in the glass. The tungsten electrodes that were beaded in this manner were then fused into the quartz container. A diagram of the cell used is shown in figure 1. In the cases of sodium chloride (NaCl) and potassium chloride (KCl) measurements were also made by filling the quartz cell directly and attaching the cell to a vacuum line. In such instances slowly raising the temperature of the solid while maintaining a pressure less than $10^{-4}$ millimeter of mercury gave satisfactory results.

The quartz cells were fitted with Chromel-Alumel thermocouples and covered with asbestos after having been suitably wrapped with high-temperature resistance wire. The heating wire was carefully wrapped to reduce the presence of temperature gradients. The temperature gradients were induced by using a I0ohm coil of resistance wire placed about one electrode. These heating units were supplied by two variable stepdown transformers. Steady-state temperatures could be controlled to within 1 percent. Voltage measurements were made by means of a voltmeter with a high internal impedance. Current-voltage plots were made with an $\mathrm{X}-\mathrm{Y}$ recorder.

It was found that, if a salt hydrate was submitted to the ammonia treat- 


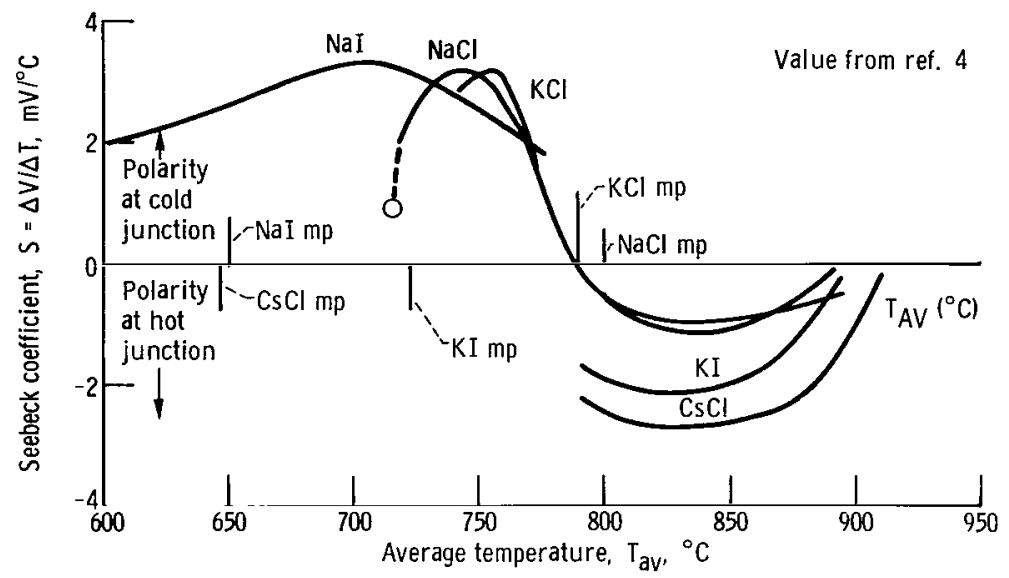

Figure 2. - Seebeck coefficients of Alkali Halides.

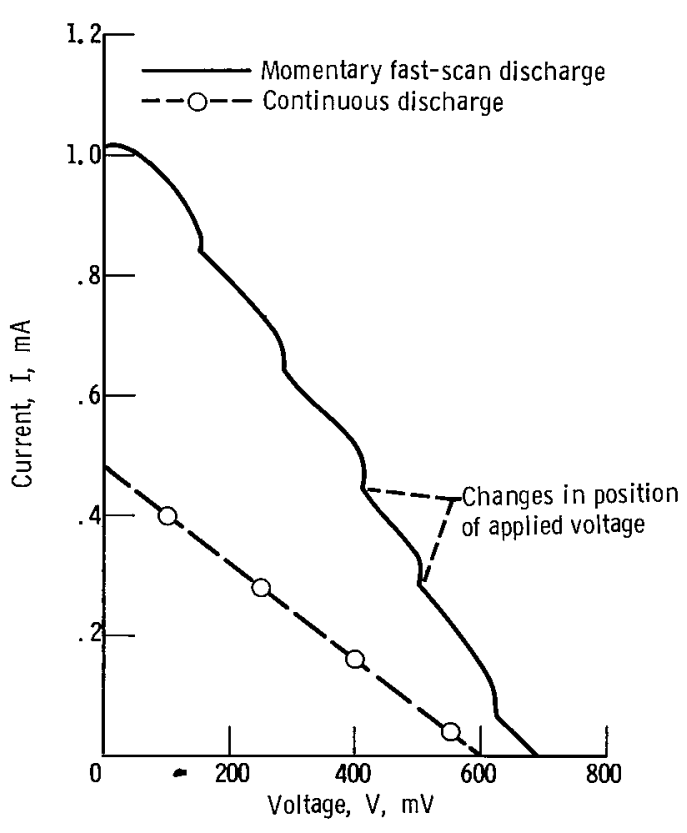

Figure 3. - Plot of continuous discharge currents for cesium chloride. Polarity at hot junction; temperature range, $720^{\circ}$ to $1002^{\circ} \mathrm{C}$; average temperature, $852^{\circ} \mathrm{C}$; Seebeck coefficient, 2. 39 millivolts per ${ }^{\circ} \mathrm{C}$. ment (e.g., LiI - $\left.3 \mathrm{H}_{2} \mathrm{O}\right)$, a solution formed that persisted at room temperature. This solution consisted of water, ammonia, and the salt. Pretreatment of the hydrate, which involved heating it in vacuum, was necessary in these cases. A volume expansion of the salt was observed in each system as a result of the ammonia treatment. In order that no residual ammonia would be present while measurements were being made, the cell was heated with a yellow flame until no pressure rise above $10^{-4}$ millimeter of mercury was observed. The cell was then removed from the vacuum line.

\section{RESULTS}

The values of the Seebeck coefficients observed are plotted in figure 2 , and the values for the discharge currents in cesium chloride ( $\mathrm{CsCl}$ ) are shown in figure 3.

In order to obtain a possible indication of the number of mobile species present, the cells were allowed to discharge

under their own thermopotential. The short-circuit currents observed were of the order of milliamperes; however, because of polarization by decomposition products, these currents were short-lived. However, CsCl did maintain steadystate currents, possibly because of the increased solubility of decomposition products.

One of the principal sources of error in the measurements was introduced by too rapid a heating or cooling rate. In all cases the salt was initially melted to ensure thermal equilibrium. To determine thermopotential values be- 
low the melting point, it was necessary to obtain as nearly a single crystal as possible. Too rapid a cooling rate would result in a polycrystalline material. Both of these conditions led to nonreproducible measurements of temperature and voltage. In addition, too rapid a cooling rate affected the quartz-tungsten seals. Since these seals are essentially of a compression type, they work well at high temperatures. When these seals were cooled to lower temperatures quickly, a crack would sometimes develop.

Although the lithium halide salts were run repeatedly, no reproducible results were available. This may have been due to the failure to remove all impurities (water, ammonia) as well as the accumulation of insoluble decomposition products at the electrodes.

\section{DISCUSSION}

The thermopotential of the $\operatorname{cell} \Delta \varphi$ is a function of several terms (ref. 2):

$$
\Delta \varphi=\Delta \varphi_{\text {hom }}+\Delta \varphi_{\text {net }}+\Delta \varphi_{e l}
$$

where

$\Delta \varphi_{\text {hom }}$ thermopotential evolved in salt as result of thermal gradient

$\Delta \varphi_{\text {net }}$ potential due to reaction at electrodes

$\Delta \varphi_{e l}$ potential due to having metal electrodes at two different temperatures

Since $\Delta \varphi_{e l}$ is of the same order of magnitude as observed for metallic thermocouples and is of the order of microvolts, its effect can be considered as being negligible for these systems. Since there is a negligible current flowing through the cell and therefore there are no elemental components with which to constitute a half-cell at the electrodes, $\triangle \varphi_{\text {net }}$ may be considered as being negligible (ref. 3). The observed thermopotentials are therefore a function of $\Delta \varphi_{\text {hom }}$ :

$$
\Delta \varphi_{\text {hom }} \propto-\sum_{R}\left(\frac{t_{R}}{z_{R}}\right) \frac{Q_{\mathrm{R}}^{\mathrm{xx}}}{T_{\mathrm{av}}}
$$

where

$\begin{array}{ll}t_{R} & \text { transference number of species } R \\ Z_{R} & \text { algebraic valence of species } R \\ Q_{R}^{X x} & \text { reduced heat of transport, } T\left(S_{R}^{X}-S_{R}\right) \\ S_{R}^{X} & \text { entropy of transport of species } R \\ S_{R} & \text { partial entropy of species } R\end{array}$


The observed thermopotential, being a function of $\Delta \varphi_{\text {hom }}$, can be written

$$
\Delta \varphi \propto-\sum_{R}\left(\frac{t_{R}}{z_{R}}\right) \frac{Q_{R}^{x x}}{T_{a v}}
$$

For NaCI this is

$$
\Delta \varphi \propto-t_{\mathrm{Na}}+\frac{\mathrm{Q}_{\mathrm{Na}}^{\mathrm{XX}}}{\mathrm{T}_{\mathrm{av}}}+t_{\mathrm{Cl}}-\frac{\mathrm{Q}_{\mathrm{CI}}^{\mathrm{xx}}}{\mathrm{T}_{\mathrm{av}}}
$$

If the effects of temperature on the values of equation (3) are examined, a qualitative description of the ion processes involved when the NaCl system, for example, is heated from about $700^{\circ}$ to $900^{\circ} \mathrm{C}$ can be evolved. It is known that the electrical conduction of solid alkali halides is a function of cation migration (ref. 4). The lower temperature values of the thermopotential are therefore due to cation migration from the hot to the cold zone. This results in a negative polarity at the hot junction. Since the values for the reduced heats of transport $Q_{\mathrm{R}}^{\mathrm{X}}$ increase with temperature, the value of the thermopotential in the solid, where it is primarily a function of cation movement, can only go through a maximum if the transport number of the cation decreases. This would be due to the onset of anion conduction. A decrease in cation transference number with increasing temperature has also been observed in other systems (ref. 5). When the anion begins to contribute to the conduction of the system, it does so not only because of the influence of heat, but also because of the electrical potential established by the prior migration of cations. The rate of change of the entropy of transport for the anion as the temperature increases must therefore be large. The result of this is that, although the transport number of the anion is low, the product of the transport number and the reduced heat of transport of the anion is large and the value of the See-

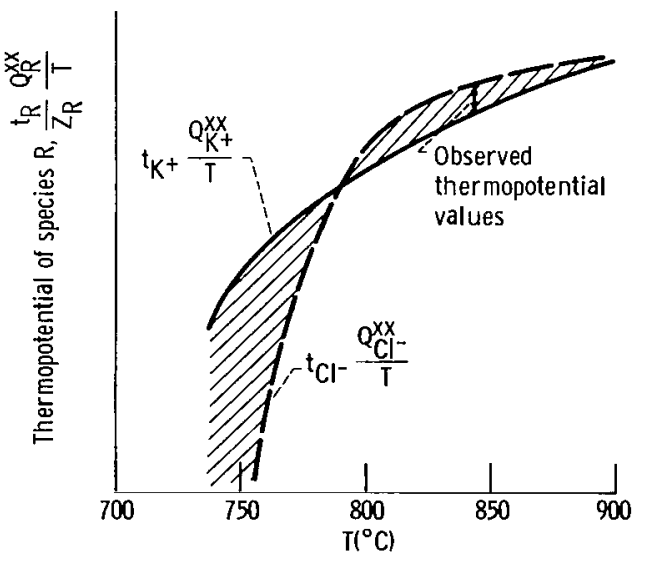

Figure 4. - Thermopotentials of potassium chloride plotted by difference of ion functions. beck coefficient goes to zero and then to a maximum of opposite polarity at the hot junction to the one initially observed at lower temperatures. As the temperature is raised further, the values of the transport numbers and associated ion entropies become nearly equal and the value of the Seebeck coefficient becomes minimal. In effect, therefore, in $\mathrm{NaCl}$ the transport number of $\mathrm{Na}^{+}$goes from 1.0 to $\sim 0.5$ and the transport number of $\mathrm{Cl}^{-}$goes from $\mathrm{O}$ to $\sim 0.5$.

Since the value of the thermopotential in equation (3) is the result of the difference between two terms, it is possible to show this by graphically representing the terms themselves. This is shown in figure 4. 
From the magnitude of the potentials measured, it can be assumed that only a fraction of the ions present are actually mobile. An estimate of the number of mobile species can be made from the short-circuit currents observed when the cells were allowed to discharge under their own thermopotential. For a discharge time of $I$ second, the number of equivalents of salt which are dissociated to form mobile species are

$$
\frac{10^{-3} \mathrm{~A} \times 1 \mathrm{sec}}{96500 \mathrm{C}} \cong 10^{-8} \text { equivalents }
$$

The discussion of transport phenomena concerns a relatively small fraction of dissociated species moving with respect to a much larger mass of undissociated species. The observed discharge currents were much higher ( $\mathrm{mA}$ ) than those observed for zinc chloride and lead chloride ( $\mu \mathrm{A})$ (ref.6). This would indicate a larger degree of dissociation and consequently higher electrical conductivities observed in alkali halide melts.

It is interesting to note that the inflection points for the plot of seebeck coefficients of $\mathrm{NaCl}$ and $\mathrm{KCl}$ as a function of temperature occur relatively close to the melting point. This is not the case for sodium iodide (NaI). In the latter case it appears that the anion contribution to the thermopotential does not appear until about $50^{\circ} \mathrm{C}$ above the melting point. Thermopotential measurements of this kind can be used to make some inferences concerning the migration of the ion species as a function of temperature.

\section{CONCLUDING RFMARKS}

It has been shown that large thermopotentials are developed in alkali halide systems within a few hundred degrees on either side of the melting point. The fact that steady-state currents can be drawn from CsCl suggests that these systems continue to be evaluated as possible thermoelectric materials.

Since the values of the Seebeck coefficient at certain temperatures are large, it would be of interest to increase the current carrying ability of the system. In future work alkali halide melts should be doped with alkali metals in an attempt to impart some electronic conduction to the system.

Lewis Research Center, National Aeronautics and Space Administration, Cleveland, Ohio, October 4, 1965.

\section{REFERENCES}

1. Greenberg, J.; and Warshawsky, I.: Visible Absorption Spectra of Iithium, Sodium, and Potassium in Molten Lithium Chloride-Potassium Chloride. J. Am. Chem. Soc., vol. 86, no. 17, Sept. 5, 1964, pp. 3572-3574. 
2. Holtan, H., Jr.; Mazur, P.; and deGroot, S. R.: On the Theory of Thermocouples and Thermocells. Physica, vol. 19, Nov. 1953, pp. 1109-1118.

3. Greenberg, Jacob; Weber, Donald E.; and Thaller, Iawrence H.: Thermopotential Measurements for Molten Cadmium Chloride, Cadmium Bromide, and Lead Chloride. J. Phys. Chem., vol. 67, no. 11, Nov. 1963, pp. 2245-2247.

4. Christy, R. W.; Hsueh, Y. W.; and Mueller, R. C.: Thermoelectric Power of $\mathrm{NaCl}$ Containing $\mathrm{CdCl}_{2}$. J. Chem. Phys., vol. 38, no. 7, Apr. 1, 1963, pp. 1647-1651.

5. Duby, Paul F.: A Contribution to the Study of Electrical Transport in Molten Salts. Ph.D. Thesis, Columbia Univ., 1962.

6. Greenberg, Jacob; Thaller, Lawrence H.; and Weber, Donald E.: A Possible Regenerative, Molten-Salt, Thermoelectric Fuel Cell. NASA TN D-2440, 1964. 
"The aeronautical and space activities of the United States sball be conducted so as to contribute . . . to the expansion of human knowledge of phenomena in the atmospbere and space. The Administration shall provide for the widest practicable and appropriate dissemination of information concerning its activities and the results thereof."

-National aeronautics and Space ACt of 1958

\section{NASA SCIENTIFIC AND TECHNICAL PUBLICATIONS}

TECHNICAL REPORTS: Scientific and technical information considered important, complete, and a lasting contribution to existing knowledge.

TECHNICAL NOTES: Information less broad in scope but nevertheless of importance as a contribution to existing knowledge.

TECHNICAL MEMORANDUMS: Information receiving limited distribution because of preliminary data, security classification, or other reasons.

CONTRACTOR REPORTS: Technical information generated in connection with a NASA contract or grant and released under NASA auspices.

TECHNICAL TRANSLATIONS: Information published in a foreign language considered to merit NASA distribution in English.

TECHNICAL REPRINTS; Information derived from NASA activities and initially published in the form of journal articles.

SPECIAL PUBLICATIONS: Information derived from or of value to NASA activities but not necessarily reporting the results of individual NASA-programmed scientific efforts. Publications include conference proceedings, monographs, data compilations, handbooks, sourcebooks, and special bibliographies.

Defails on the availability of these publications may be obtained from:

SCIENTIFIC AND TECHNICAL INFORMATION DIVISION

NATIONAL AERONAUTICS AND SPACE ADMINISTRATION

Washington, D.C. 20546 